EPJ Web of Conferences 56, 03002 (2013)

DOI: $10.1051 /$ epjconf/20135603002

(C) Owned by the authors, published by EDP Sciences, 2013

\title{
Moisture levels and drying potential of the concrete in Swedish reactor containments
}

\author{
M. Oxfall ${ }^{1,2, a}$, M. Hassanzadeh ${ }^{1,2}$, P. Johansson ${ }^{2}$ \\ ${ }^{1}$ Vattenfall Research and Development AB, Sweden \\ ${ }^{2}$ Lund University, Division of Building Materials, Sweden
}

\begin{abstract}
The climatic conditions inside nuclear reactor containments are continuously monitored by the plant owners in order to e.g. maintain a suitable climate for the mechanical and electrical equipment. Due to the high temperatures, during operation, the concrete within the containment may act as a moisture source contributing to the humidity. To evaluate if, and to what extent, the concrete inside the containment influences the climatic conditions, the moisture distribution has to be determined. In order to do this, a measurement setup has been developed and tested. The results showed that the measurement setup was suitable for long term measurements of internal relative humidity in concrete. However, measurements close to the concrete surfaces showed tendencies of leakage, increasing the uncertainties of those measurements. The measurement setup was installed at three reactor containments in Sweden during the summer of 2012. Results from the monitoring campaign on one of the three reactor containments are presented in this paper. The results showed that the concrete was still drying after 30-35 years of exposure inside the containment.
\end{abstract}

\section{Introduction}

The reactor containment (RC) is the structure at a nuclear power plant (NPP) where the reactor is located. There are several types of NPP and each may have a different design of the RC, and the materials which are constituents of internal and external structures can vary depending on manufacturer. In Sweden two types of NPP:s are used, Boiling Water Reactor (BWR) and Pressurized Water Reactor (PWR). In both types the RC-wall consists of a concrete wall with a steel liner. The steel liner is located in the concrete at a depth of ca. $300 \mathrm{~mm}$ from the inner surface and is used to ensure leak tightness. The concrete protects the liner from e.g. impacts and corrosion.

Regardless of the design there are large quantities of concrete inside the RC. Apart from the RCwall there are different types of internal structures, such as the thick concrete structure to shield of the radiation from the reactor tank.

The major difference between the amount of concrete enclosed in Swedish RC:s can be seen between BWR:s and PWR:s, were a PWR can contain up to $8000 \mathrm{~m}^{3}$ concrete inside the liner, while the corresponding amount is $2000 \mathrm{~m}^{3}$ for a BWR. However, when comparing the air to concrete volume ratio between the RC:s they are quite similar, with the ratio corresponding to ca. $6: 1$.

\footnotetext{
a e-mail: Mikael.Oxfall@vattenfall.com
}

This is an Open Access article distributed under the terms of the Creative Commons Attribution License 2.0, which permits unrestricted use, distribution, and reproduction in any medium, provided the original work is properly cited. 
The RC in a BWR can be divided into three main compartments, usually called upper dry-well, lower dry-well and wet-well. A schematic illustration on a BWR is presented in Figure 1. The wetwell is separated from the upper dry-well with an intermediate floor and from the lower dry well with a thick cylindrical concrete wall. A PWR can be described as a large space that includes several internal structures on different levels.

All concrete surfaces inside the RC:s in the Swedish NPP:s has an epoxy coating, which was applied during construction. The main purpose of the coating is to prevent contaminated dust and other materials to be absorbed on the concrete surface. One supplementary effect of the epoxy coating is that the drying of the concrete will be slower due to an increased diffusion resistance of the surface.

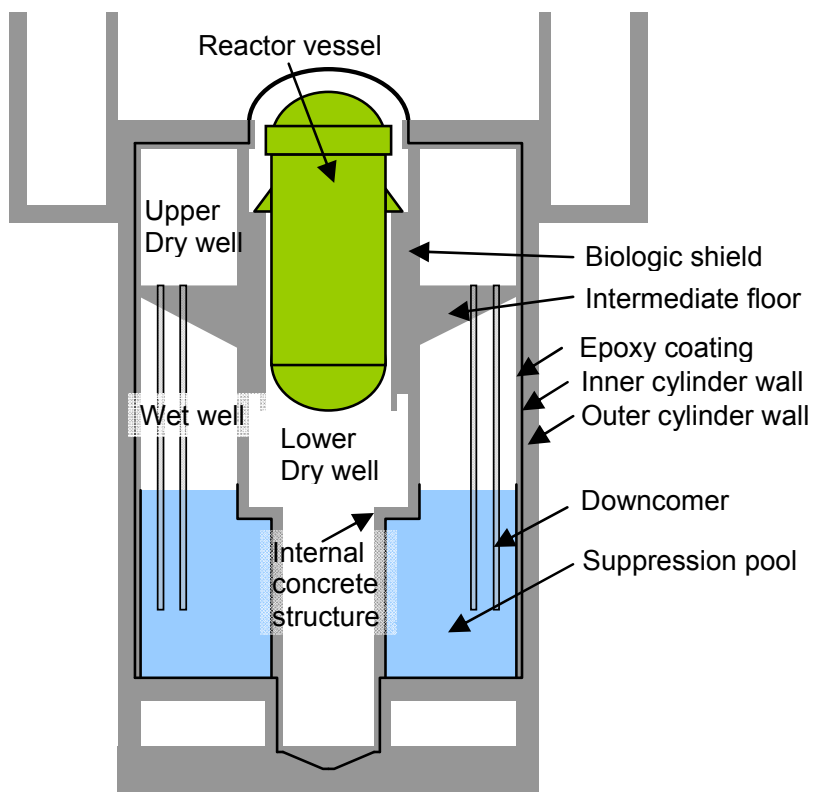

Fig. 1. Schematic illustration of a BWR RC, the line inside the concrete structures corresponds to the steel liner.

The Swedish NPP:s were all built during a period from the late $1960^{\text {th }}$ to the mid- $1980^{\text {th }}$. The climate inside the containments is monitored continuously by the plant owners. The purpose of these measurements is mainly to monitor the temperature in specific zones close to sensitive equipment and is therefore not suitable to describe the overall climatic conditions. Regardless of NPP the temperature inside the $\mathrm{RC}$ can reach up to $50-60^{\circ} \mathrm{C}$ in some zones. Considering the extreme climate, it is of great importance to evaluate how this affects the concrete and what drying rate that can be expected.

Creep and shrinkage of concrete as well as several degrading mechanisms are all dependent on the temperature and moisture content of the concrete. Apart from this, Thorne [1] summarises some of the moisture dependent concrete properties relevant to reactor shielding e.g. neutron radiation shielding, which also was investigated by Hilsdorf [2], thermal conductivity, heat diffusivity and specific heat capacity. The moisture content also influences other material properties such as moisture and gas permeability [3].

The concrete inside the RC:s may act as a moisture source affecting the climatic condition inside the RC. Fresh concrete consists of a large quantity of water. During the hydration phase a certain amount of water will be chemically and physically bound in the cement gel but the remaining part, evaporable water, can be dried out over time. What effect this water have on the climatic condition depend on the drying rate and thereby the temperature and humidity variations inside the RC:s.

The moisture content in concrete have been studied internationally on several fields, mainly focusing on drying of concrete slabs and walls in buildings e.g. $[4,5]$, the moisture contents 
influences on creep and shrinkage e.g. [6-10] and frost related damages e.g. [11, 12]. Most moisture related studies on concrete have been carried out in laboratory controlled environment or as simulations and only a few studies have been on environmental effects in the field e.g. [13, 14]. No extensive studies could be found on measurements in an RC but a few studies where the moisture levels inside the concrete was estimated can be found [2, 15]. Additionally, some measurements of relative humidity have been done on the containment wall outside of the liner [15-17].

There are several ways to measure and to quantify the moisture content. For instance degree of saturation and degree of capillary saturation, which are normally used in the cases with high moisture content. In hygroscopic conditions, however, the moisture content is normally quantified by means of equilibrium relative humidity $(\mathrm{RH})$ and/or moisture ratio. Several of the methods require direct measurements on specimens and thereby destructive testing. In field measurement, where it is not possible to do destructive testing and when the moisture distribution is monitored over time indirect methods such as RH is a suitable method.

In field measurements the effects from known and unknown heat and moist sources has to be considered. The measurement setup has to be constructed so that it can be reliable over time. Most measurements reported in literature, concerning specimens exposed to field environment, were conducted on specially fabricated test specimens $[13,14,18]$ with cast in measurement devises. When measuring on existing structures the measurement setup has to be installed on site leading to a greater uncertainty. In this study a measurement setup for field measurements is designed and evaluated in monitoring campaigns on three NPP:s in Sweden. Prior the monitoring campaign an accuracy evaluation of the setup was performed in a laboratory environment. Results from the accuracy evaluation will be presented in a forthcoming paper.

\section{Method}

This study consists of monitoring campaigns on three NPP:s in Sweden and an accuracy evaluation. The monitoring campaign was performed on two BWR:s and one PWR. In this paper only results from the first ca 80 days in one monitoring campaign at a BWR is presented. The BWR is here called BWR 1 and it has been in operation ca. 35 years.

\subsection{Measuring equipment}

The equipment used for the monitoring campaign consisted of $\mathrm{RH}$ and temperature measurement probes, HMP 110, from Vaisala Oy, Finland. The probe measures RH with a Vaisala HUMICAP® 180R sensor and the temperature with Pt1000 RTD, 1/3 Class B IEC 751. The uncertainty data from the manufacturer on the probe are presented in Table 1.

Table 1. Uncertainty for measuring probes according to manufacturer, Ref. B210852EN-A @V Vaisala, Vaisala Oy, 2010

\begin{tabular}{|c|c|c|c|c|c|}
\hline & Range & $\begin{array}{c}\text { Uncertainty } \\
-40-0^{\circ} \mathrm{C}\end{array}$ & $\begin{array}{c}\text { Uncertainty } \\
\mathbf{0}-+40^{\circ} \mathrm{C}\end{array}$ & $\begin{array}{l}\text { Uncertainty } \\
+40-+80^{\circ} \mathrm{C}\end{array}$ & Stability [2 years] \\
\hline \multirow[t]{2}{*}{ HUMICAP 180R } & $0-90 \%$ & $\pm 3.0 \%$ & $\pm 1.7 \%$ & $\pm 3.0 \%$ & $\pm 2.0 \%$ \\
\hline & $90-100 \%$ & $\pm 4.0 \%$ & $\pm 2.5 \%$ & $\pm 4.0 \%$ & $\pm 2.0 \%$ \\
\hline Pt1000 1/3 Class B & $-40-+80^{\circ} \mathrm{C}$ & $\pm 0.4{ }^{\circ} \mathrm{C}$ & $\pm 0.2^{\circ} \mathrm{C}$ & $\pm 0.4^{\circ} \mathrm{C}$ & \\
\hline
\end{tabular}

All probes came with a calibration certificate from the manufacturer performed at $20^{\circ} \mathrm{C}$. The probes were thereafter calibrated at Division of Building Materials, Lund University, in a moisture 
precision chamber, Model 2500 Humidity generator, from Thunder scientific corporation, New Mexico, U.S.A. The calibration was done with the same cables and loggers that were used in the monitoring campaign.

The calibration was done in two temperatures, 20 and $50^{\circ} \mathrm{C}$, and the $\mathrm{RH}$ was $50,75,85$ and 95 $\%$ at both temperatures. All probes will be calibrated after the measurements to detect if the probes have drifted during the measuring period.

Both temperature and $\mathrm{RH}$ were measured in millivolt $(\mathrm{mV})$ in the interval of $0-2500 \mathrm{mV}$. The temperature measuring range of the probes was $-40{ }^{\circ} \mathrm{C}$ to $+80{ }^{\circ} \mathrm{C}$ and the $\mathrm{RH}, 0-100 \%$. In tables and graphs the data has been converted into ${ }^{\circ} \mathrm{C}$ and $\% \mathrm{RH}$ according to the calibrations done in Lund.

\subsection{Measurement setup}

Measurements in the concrete required several sealings to minimize or eliminate leakage from/to the surroundings. The measurement setup consisted of a casing pipe with four sets of sealings, see Figure 2. The casing pipe had a diameter of $16 \mathrm{~mm}$ and was made of polypropylene plastic. The inner volume was sealed with a rubber o-ring, which also fixated the probe in the pipe. At the inner end of the casing pipe a rubber plug with a diameter of $17 \mathrm{~mm}$ was used to seal of the edges of the bottom to separate the surface that was measured. The sealants used to close the opening gap were SikaFlex AT-Façade and SikaFlex AT-Connection was used to seal the outer opening of the casing pipe.

A leak tightness test of the inner plug when installed in a hole and the tightness of the o-ring was done with adequate result using a bellow prior the monitoring campaign. The tightness of the opening gap sealer was not tested in this study but SikaFlex AT-Connection has been used in previous studies for sealing with good results at Lund University, division of Building Materials [17, 19]. Both sealants, Connection and Façade, were a 1-component silane terminated polymers with similar properties according to the manufacturer.

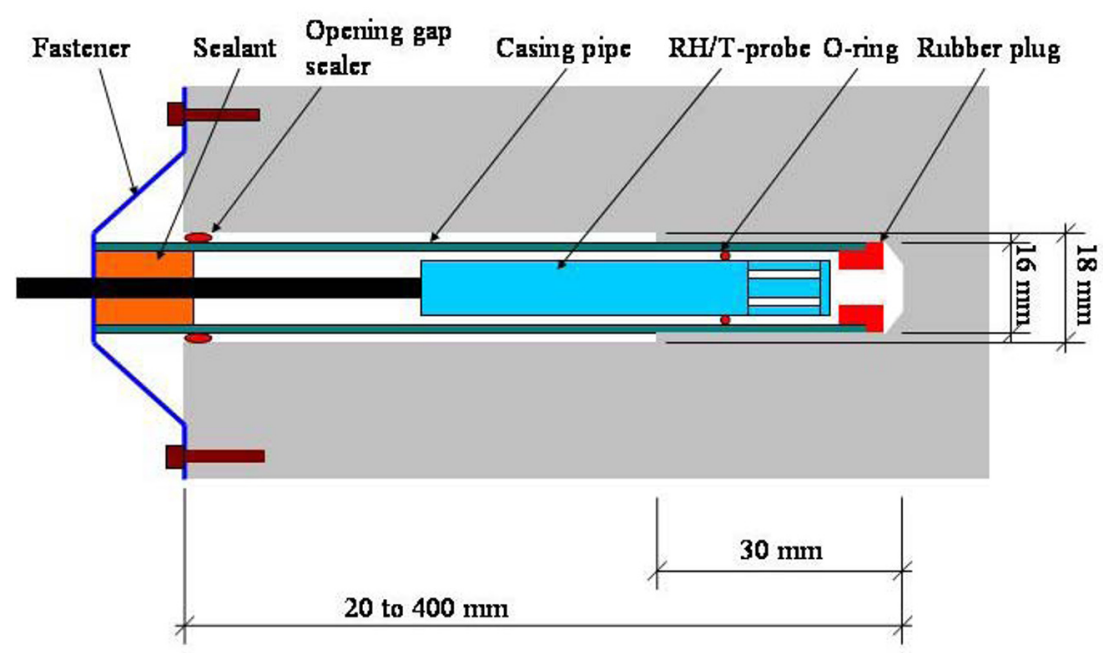

Fig. 2. Measurement setup for monitoring of RH and temperature in concrete with a Vaisala HMP 110 probe

The holes were hammer-drilled and no water cooling was used to avoid adding moisture to the concrete. The lack of cooling resulted in a temperature increase in the concrete and possible drying which is a problem if the measurements are done shortly after. The temperature effect will not be a problem within this study since the measuring equipment was installed and left in the holes the entire period. A diamond drill was not used in order to minimize the risk of damaging reinforcement or the steel liner in case of an accidental impact. 
The holes that were deeper than $30 \mathrm{~mm}$ had a diameter of $18 \mathrm{~mm}$ on the outer section and the inner $30 \mathrm{~mm}$ had a diameter of $16 \mathrm{~mm}$, see Figure 2. This was done to reduce the friction between the casing pipe and concrete. To eliminate the drill cuttings the holes were cleaned with a vacuum cleaner and a pipe cleaner. It was of utmost importance to eliminate as much as possible because left drill cuttings could affect the leak tightness and moisture fixation and thereby the measured $\mathrm{RH}$ in the holes. The boreholes depth was measured during drilling and controlled after so that the actual depth was within $\pm 2 \mathrm{~mm}$ from the expected.

The measurement setup was installed in the hole and fixated with the opening gap sealant and a corrugated fastener which pressed the casing pipe and inner plug against the bottom of the holes using two concrete screws.

To lower the temperature influence on the casing pipe and the probes, the end of the casing pipe were insulated with a 2-3 mm thick EPDM rubber sheeting.

\subsection{Monitoring campaign}

The monitoring campaigns were executed at three NPP:s in Sweden, where only BWR 1 is presented here. All measurement setups were installed in different zones inside each RC. The zones were chosen to represent as big part as possible, from the bottom to the top of the RC. No zones were placed close to known heat or moisture sources. All probes used were calibrated according to section 2.1. The measurements were conducted over one operational year and they started during the summer months of 2012.

The measurements were divided into primary and secondary measurements. The primary measurements consisted of one probe measuring the boundary conditions close to the concrete surface and four setups to measure in the concrete on up to four depths. The secondary measurements consisted of one probe measuring the boundary conditions and two setups measuring the concrete. The secondary measurements were done to verify that the primary measurements were representative for a larger part of the RC.

In total 25 measurement probes were used at BWR 1. Of these, 20 were mounted in the drilled holes in the concrete and the rest were installed ca $5 \mathrm{~cm}$ from the concrete surfaces to measure boundary conditions in the air. There were four primary measurements and two secondary measurements. The zones used for the primary measurements were located at the inner RC-wall in the upper dry-well, the intermediate floor and in the wall between lower dry-well and wet-well. The secondary zones were both in the inner RC-wall. In Table 2 the positions for the primary and secondary zones are presented.

Table 2. The position of RH- and temperature probes for each zone at BWR 1. Four primary (P) measurements and two secondary (S) was conducted. Depth represents the depth on which the measurements were conducted.

+ Heights are the vertical location and distance from centre and angel describes the horizontal location.

\begin{tabular}{|c|c|c|c|c|}
\hline Zone & Depth [mm] & + Heights [m] & Distains from centre [m] & Angle [ ${ }^{\circ}$ ] \\
\hline 1P & Air: 20: 50: 150: 250 & 112 & 11.00 & 120 \\
2P & Air: 20: 50: 150: 250 & 103 & 11.00 & 195 \\
3P & 20: 50: 150: 400 & 103 & 10.00 & 195 \\
4P & Air: 20: 50: $150: 400$ & 96 & 5.80 & 40 \\
S1 & Air: 50: 150 & 115 & 11.00 & 240 \\
S2 & Air: 50: 150 & 106 & 11.00 & 30 \\
\hline
\end{tabular}




\section{Results and discussion}

The results from the firs 80 days of measurements on BWR 1 are presented in Figure 3. P corresponds to the primary measurements and $\mathrm{S}$ to the secondary measurements as described in Table 2. The measurements included the start-up of the reactor after 15 days.
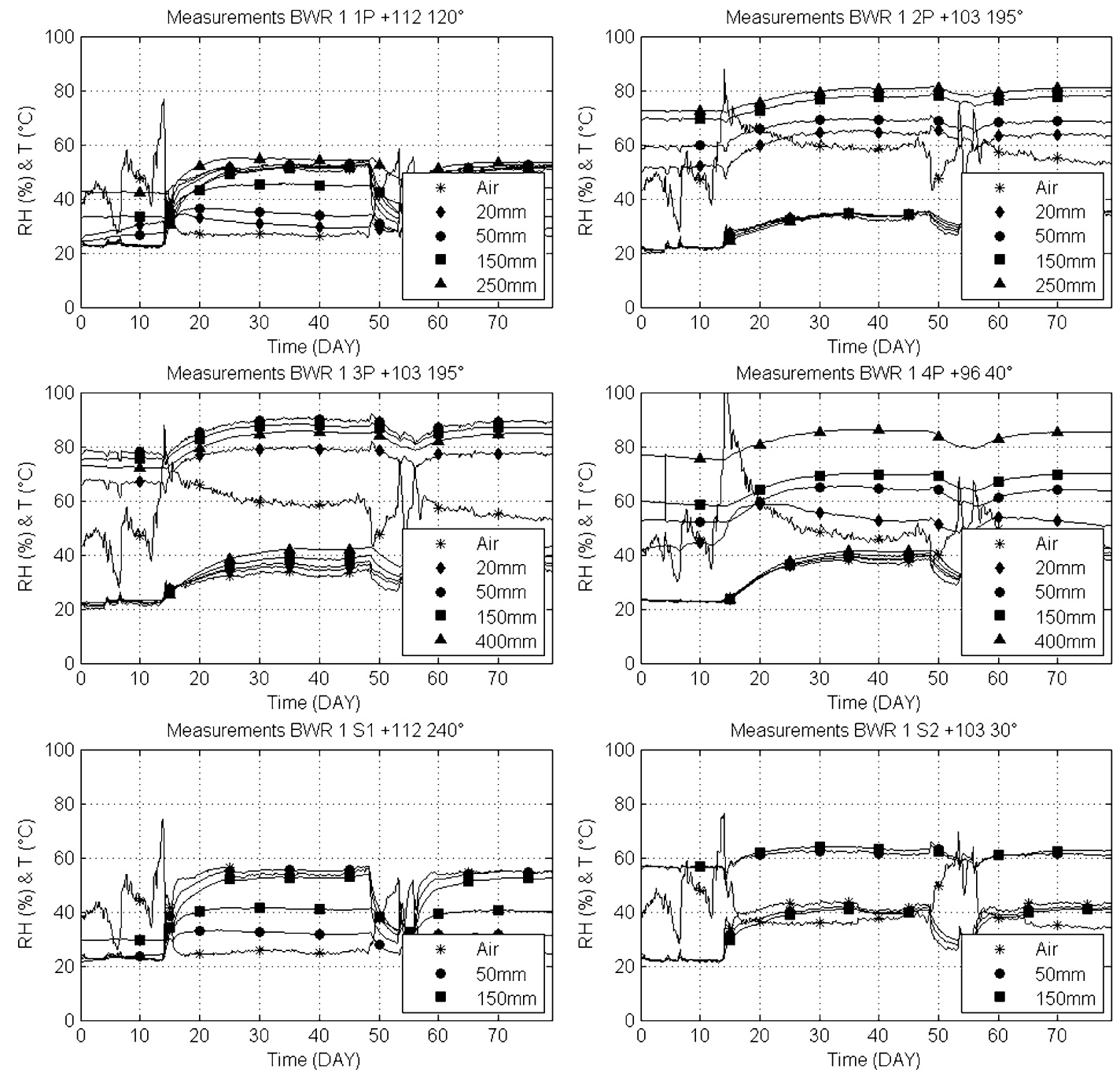

Fig. 3. Measurements of internal RH and temperature in concrete at BWR 1. The measuring period was from 2012-06-08 to 2012-08-27 giving a total of some 80 days. The reactor started after 15 days in to the monitoring campaign and is seen as a rapid temperature increase. The RH is presented in the figure with symbols at even 10 days and the temperature is presented with symbols at 15, 25, 35 days etc.

All measurements were done as single value measurements with calibrated equipment. The results showed that the measurement setup worked on long term field measurements. Suspected leakage was however observed at a couple of the setups. The most distinct leakage was observed on two measurement setups in $1 \mathrm{P}$ and $4 \mathrm{P}$, Figure 3. In the zones the suspected leakage occurred in the measurement setups on $20 \mathrm{~mm}$ depth. This points out that the installation of the probes is a crucial step especially for the shallower depth. 
One possible error with the setup is if the measured surface would entirely be in an aggregate. This scenario would probably affect the measurements due to differences in material properties of the surrounding cement and the aggregate. The most common rock in the Swedish aggregates is granite. The moisture transport coefficient was measured by Wessman [20] on one type of Swedish granite. When compared with the moisture transport coefficient on concrete, with data from [21], similar to that used at BWR1 the concrete had an coefficient ca 10-30 times higher then the granite. The vapour content in the aggregate pores should however be the same as in the cements at equilibrium. This is also likely to be the case here, even though the structure is slowly drying. Due to the lower moisture transport through the aggregate there would however take a longer time for the cavity, on which the measurements is done, to reach equilibrium with the surface. This would result in an initial RH close to the boundary condition and thereafter a change of RH during the firs period of time. Eventually, at equilibrium, the measured RH would be similar to that obtained if the measured surface contained cement past. Even a small amount of cement on the surface would however drastically decrees the time needed to reach equilibrium due to faster moisture transport. No clear evidence of such results was observed from the measurements, indicating that there was no setup that only measured in an aggregate. This will be feather analyst through visual inspection during dismantling.

A second possible error may be due to the usage of a hammer-drill. During the drilling this could result in some superficial crack formation in the concrete. To what extent this could affect the readings has not been investigated.

From the measurements it is shown that the temperature varied in the $\mathrm{RC}$ with the highest temperature on high levels. The highest temperature, ca. $55^{\circ} \mathrm{C}$, was observed at $1 \mathrm{P}$ and $\mathrm{S} 1$ at +112 , Figure 3, and a clear correlation between high temperatures and low RH in the concrete could be seen.

The measurements show that in almost all zones there was a moisture profile in the concrete, see Figure 4 and 5. This indicates that the concrete is still drying after 30-35 years of exposure in high temperatures and that the moisture stored in the concrete is contributing to the climatic condition inside the containments.
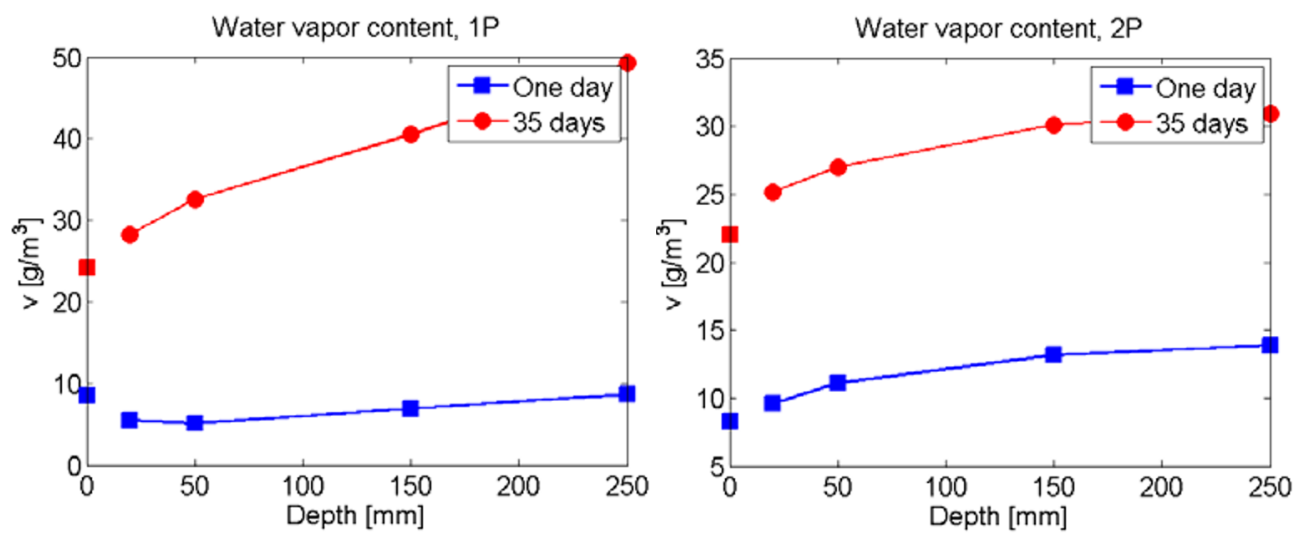

Fig. 4 and 5. Water vapour content profiles in the inner cylinder wall in zone $1 \mathrm{P}$ and $2 \mathrm{P}$. The data used was after one and 35 days of measurements. The points at $0 \mathrm{~mm}$ depth correspond to the boundary condition. The water vapour content was calculated from the measured $\mathrm{RH}$ and temperature presented in Figure 3.

\section{Conclusions}

The results show that the measurement setup is suitable for the long term measurement of the internal RH and temperature in concrete in the interior of the RC:s. The sealing system works for all depth but extra attention has to be paid to measurements at $50 \mathrm{~mm}$ and especially at $20 \mathrm{~mm}$. 
The results from the monitoring campaigns indicate that the concrete inside the RC is still drying after 30-35 years of exposure to high temperatures and thereby contributes to the climatic conditions inside the RC. The actual contribution will be presented in a forthcoming study.

\section{Acknowledgements}

The authors would like to thank all people involved at the NPP:s for the help with the monitoring campaigns and a special thanks to; Jan Gustavsson, Johanna Spåls, Ulf Nilsson, Petter Gustavsson, Bengt Adolphsson at Ringhals and Andris Zarins, Anders Frisk, Ulf Modin and Marcus Edin at Forsmark for making these measurements possible. Finally we would like to thank the financier for this doctoral project, Elforsk Nuclear concrete program, and its board members.

\section{References}

1. C. P. Thorne, Journal of the American concrete institute 32, 1491 (1961).

2. H. K. Hilsdorf, Nuclear Engineering and Design 6, 251 (1967).

3. P. Fredlund, L.-O. Nilsson, Gas penetration in concrete reactor containments - Measurements and Modelling (In Swedish), Elforsk rapport 09:101, (Lund University, Lund, 2009).

4. M. Åhs, Doctoral Thesis, Lund University (2011).

5. L.-O. Nilsson, Doctoral Thesis, Lund University (1980).

6. H.-W. Song, S.-H. Kim, K.-J. Byun, Y.-C. Song, Nuclear Engineering and Design 217, 225 (2002).

7. Z. Grasley, D. Lange, M. D'Ambrosia, Materials and Structures 39, 901 (2006).

8. Z. Grasley, D. Lange, Materials and Structures 40, 311 (2007).

9. Z. P. Bažant, Nuclear Engineering and Design 14, 308 (1970).

10. Z. Hora, B. Patzák, Nuclear Engineering and Design 237, 253 (2007).

11. G. Fagerlund, Doctoral Thesis, Lund University (1972).

12. K. Fridh, Doctoral Thesis, Lund University (2005).

13. D.-W. Ryu, J.-W. Ko, T. Noguchi, Cement and Concrete Composites 33, 142 (2011).

14. C. Andrade, J. Sarría, C. Alonso, Cement and Concrete Research 29, 1249 (1999).

15. L.-O. Nilsson, paper presented at the SMiRT 19, Toronto, August 2007.

16. P. Johansson, L.-O. Nilsson, paper presented at the SMiRT 19, Toronto, August 2007.

17. L.-O. Nilsson, P. Johansson, Changes in reactor containments - The drying and climatic conditions in the concrete walls (In Swedish), Elforsk rapport 09:100, (Lund University, Lund, 2009).

18. C. Y. Chang, S. S. Hung, Construction and Building Materials 26, 628 (2012).

19. P. Johansson, Drying of concrete - The laboratory study for TorkaS3 (In Swedish), Report TVBM-3165, (Lund University, Lund, 2012).

20. L. Wessman, Licentiate Thesis, Lund University (1997).

21. G. Hedenblad, PhD Thesis, Lund University (1993). 